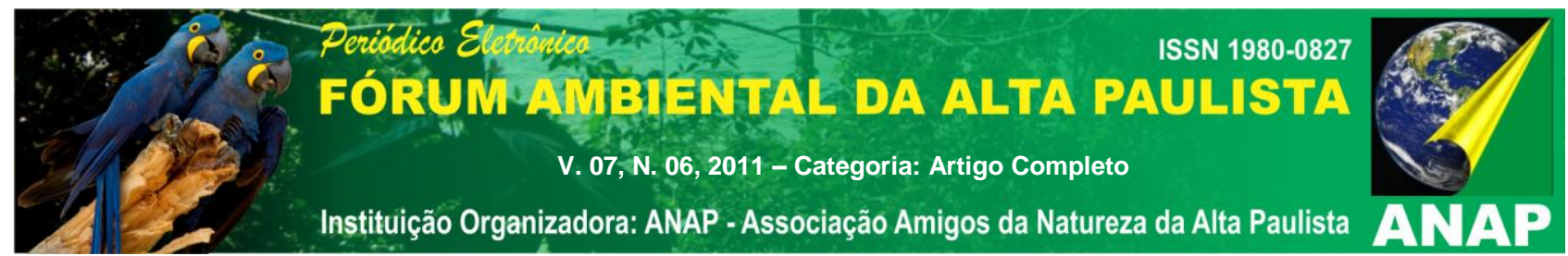

\title{
EDUCAÇÃO AMBIENTAL PARA ÁGUAS DA BACIA HIDROGRÁFICA TIETÊ - JACARÉ
}

\author{
Juliana Lopes Ruiz \\ Yanina Micaela Sammarco \\ Natalia Beniti Ribeiro \\ Noéle Fonseca Martins
}

RESUMO: O Instituto Pró-Terra vem atualmente atuando em diversos projetos de Educação Ambiental na Bacia Tietê-Jacaré. Recentemente, lançou o livro "Águas e Paisagens Educativas da Bacia Tietê-Jacaré também financiado pelos recursos do FEHIDRO. Este livro foi uma importante conquista, já que educadores e educadoras carecem de materiais didáticos para fundamentar suas atividades educativas. Neste sentido, o Instituto Pró-Terra preocupou-se em elaborar outro projeto, seguinte à construção do livro, que possibilitasse a capacitação para o uso do mesmo, já que o objetivo é que os atores socioambientais da bacia possam tirar o melhor proveito, aumentando assim suas capacidades de exercer processos de educação ambiental. Desta forma, surgiu o presente projeto "Educação Ambiental para as Águas da Bacia Hidrográfica Tietê-Jacaré" na qual a metodologia utilizada para a capacitação dos atores no desenvolvimento deste trabalho foi de palestras e dinâmicas de grupo, através da pesquisa-ação, buscando reforçar iniciativas individuais e o fomento das capacidades para a melhoria da qualidade de vida na Bacia Tietê-Jacaré. As atividades de educação ambiental deste projeto abrangeram educadores e educadoras ambientais de instituições de ensino municipal, estadual e particulares, de ONGs e de empresas privadas, além de gestores dos diferentes municípios por onde tais atividades foram desenvolvidas.

Palavras chave: Educação Ambiental; Capacitação de Educadores (as); Material Didático em Educação Ambiental.

\section{ESTRUTURA:}




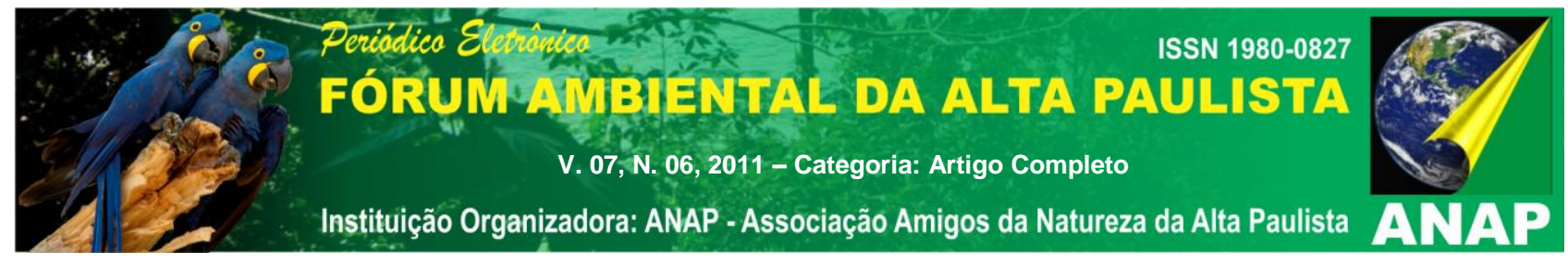

O projeto, "Educação Ambiental para as Águas da Bacia Hidrográfica TietêJacaré", foi desenvolvido em 3 etapas: Seleção dos Beneficiários e Elaboração do Cronograma de Ações; Ações de Educação Ambiental; Avaliação e Monitoramento. No entanto, tiveram algumas pequenas mudanças no decorrer do projeto para que o mesmo fosse desenvolvido com maior qualidade. Desta forma, temos que, a primeira etapa foi do mês 1 ao 5 e teve como finalidade definir as áreas e as(os) educadoras(es) beneficiários e a construção do cronograma de ações de educação ambiental, além da elaboração da atividade de educação ambiental que seria desenvolvida na segunda etapa e a realização de duas atividades para testar a metodologia. A segunda etapa foi do mês 5 ao 12 e teve como finalidade desenvolver as ações de educação ambiental e socializar com a comunidade da UGRHI Tietê-Jacaré a história dos rios, contemplando os recursos hídricos, sócio-biodiversidade e as problemáticas sócio ambientais locais através da capacitação com o livro "Águas e Paisagens Educativas da Bacia TietêJacaré". Já a terceira etapa foi realizada durante todo o projeto, tendo ênfase nos meses 2, 6 e 12, com a finalidade de se avaliar e monitorar todo o processo, de forma a atingirmos totalmente os nossos objetivos.

\subsection{INTRODUÇÃO:}

O projeto Educação Ambiental para Águas da Bacia Hidrográfica Tietê - Jacaré propôs através de capacitação com o material didático "Águas e Paisagens Educativas da Bacia Tietê - Jacaré", construído especialmente para nossa bacia hidrográfica, reforçar a capacidade de desenvolvimento de projetos em Educação Ambiental e sensibilizar os educadores(as) e gestores(as) da nossa bacia para a questão do pertencimento. As atividades de Educação Ambiental fomentaram o trabalho em equipe e destacaram importância da contextualização local dos projetos ambientais, enfatizando as realidades apresentadas em cada município. Neste contexto, o objetivo do projeto foi aguçar as perspectivas locais para construção de novos processos educativos em nossa bacia hidrográfica.e capacitar educadores para que esses processos sejam contínuos e contextualizados conforme a necessidade de cada município. A metodologia pesquisa- 


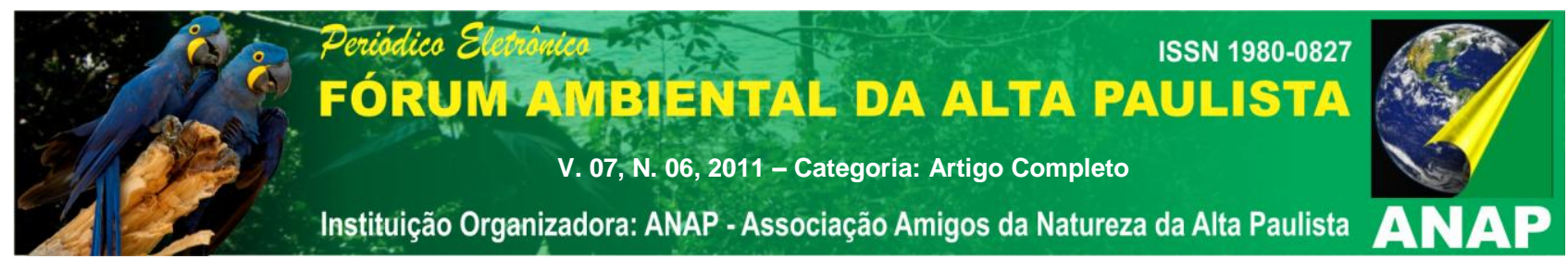

ação, utilizada nas oficinas foi explorada entre os participantes no sentido de refletirem sobre os problemas socioambientais e construírem um panorama geral da situação do município. A capacitação também permitiu a criação de um roteiro socioambiental, no qual todos os participantes puderam acessar e até propor em seus municípios.

\subsection{METODOLOGIA}

A metodologia utilizada no desenvolvimento deste trabalho buscou reforçar iniciativas individuais e busca da conscientização, através da interrelação dos pesquisadores com atores sociais, a pesquisa-ação, que permite uma representação significativa da coletividade. Segundo THIOLLENT (1996), descreve pesquisa-ação como:

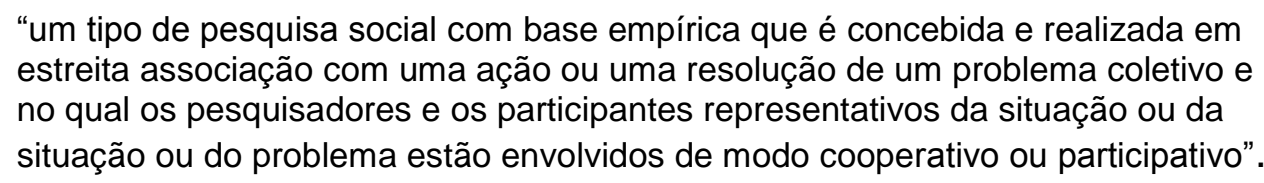

Já HUGES DIONNE (2007), conceitua a pesquisa-ação como

"prática que associa pesquisadores e atores em uma mesma estratégia de ação para modificar uma dada situação e uma estratégia de pesquisa para adquirir um conhecimento sistemático sobre a situação identificada."

Neste contexto, a proposta de atividades de educação ambiental deste projeto abrangeram espaços formais (instituições de ensino), espaços não formais (cooperativas, associações, centros culturais, etc) e espaços informais (meios de comunicação).

\subsection{Localização}

A área de abrangência do projeto foi a UGRHI Tietê-Jacaré, a qual faz parte de uma das 22 Unidades de Gerenciamento dos Recursos Hídricos do Estado de São Paulo. Essa é definida como a Unidade de Gerenciamento de Recursos Hídricos 13 (UGRHI-13) pela Lei ำ 9.034/94 que compreende as Bacias Hidrográficas dos Rios Jacaré-Guaçu e Jacaré-Pepira e seus tributários, além de porções de áreas drenadas diretamente para o Rio Tietê, no trecho situado entre a Usina Hidrelétrica de Ibitinga, a jusante, e a Usina de Barra Bonita a montante. A UGRHI Tietê/Jacaré, número 13, 


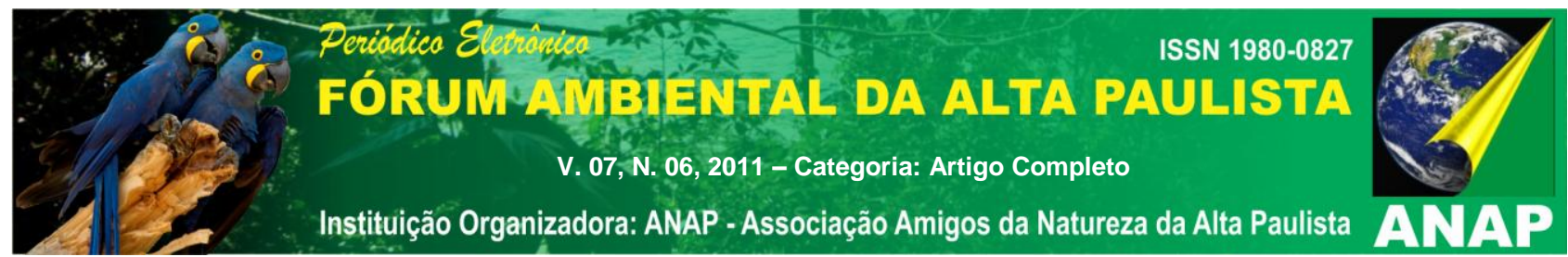

localiza-se na porção central do Estado, e faz parte da Diretoria Regional do DAEE da Bacia do Baixo Tietê, na divisa com a Bacia do Médio Tietê. Ela faz limite a norte e oeste com UGRHI-16 (Tietê/Batalha), a leste e sudeste limita-se com a UGRHI-5 (Piracicaba/Capivari/Jundiaí), a sul com as UGRHI-10 e 17 (Tietê/Sorocaba e Médio Paranapanema, respectivamente) e a nordeste com a UGRHI-9 (Mogi-Guaçu). A Bacia Hidrográfica do Tietê/Jacaré, tem sua área calculada através da base cartográfica na escala 1:250.000, totalizando $11.784,6 \mathrm{~km}^{2}$, ocupando a $14^{\text {a }}$ posição em área de drenagem entre as demais UGRHI do Estado, em ordem decrescente. O perímetro da Bacia perfaz 570 km, aproximadamente.( Relatório final $\mathrm{CBH}-\mathrm{TJ}$ ).

\subsection{DESENVOLVIMENTO:}

O Instituto Pró-Terra realizou para este projeto a seleção dos beneficiários a e elaboração de cronograma de ações junto aos seus parceiros, elaborando três reuniões para a definição dos municípios que seriam contemplados com esse projeto, para planejar a abordagem que faríamos junto a cada município e quais seriam os representantes presentes nas atividades de educação ambiental a serem desenvolvidas. Desta forma, ficou definido que as atividades de educação ambiental previstas para tal projeto deveriam abranger ao menos todos os 34 municípios da Bacia Tietê-Jacaré, podendo os demais municípios com parte de seu território nessa bacia ser também contemplados. A abordagem inicial seria feita junto às Secretarias de Educação e do Meio Ambiente, a fim de respeitar as organizações governamentais de cada município. Estabelecendo-se uma parceria junto aos municípios, enviaríamos às secretarias dos mesmos todo o material necessário para a divulgação da atividade de educação ambiental, as quais ficariam responsáveis em repassá-lo para grupos/instituições préestabelecidos. Também foi decidido que, não havendo o estabelecimento de uma parceria, partiríamos convidando diretamente as educadoras e os educadores possíveis de participar da atividade de educação ambiental esperada. Concordamos que os grupos deveriam ter no máximo 25 participantes, a fim destes poderem ser intimamente acompanhados durante todo o processo pelo facilitador e que os mesmos deveriam representar o maior número de instituições possível. Assim, os convites deveriam ser distribuídos a instituições de ensino municipal, estadual e particulares, a ONGs e 


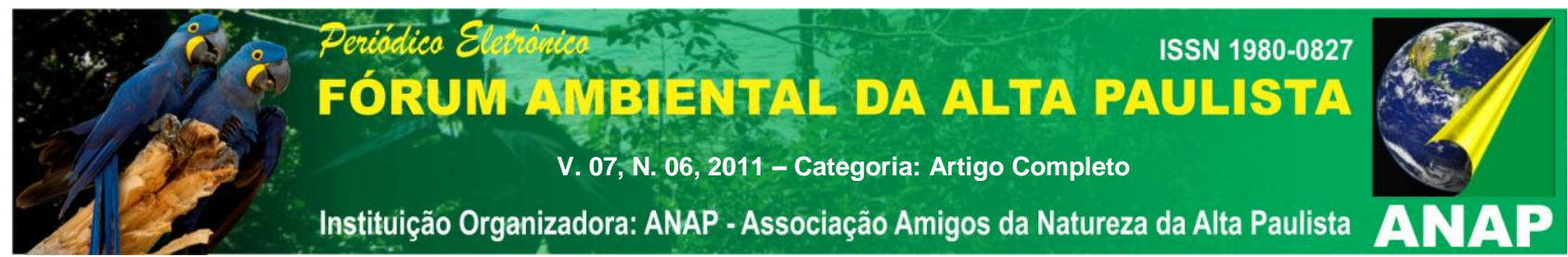

também a empresas privadas, além de deverem ser entregues à diferentes gestores municipais, sempre com a ênfase de se ter, de preferência, um representante de cada instituição, devendo o mesmo se responsabilizar em multiplicar o conhecimento adquirido com o projeto junto aos demais membros de sua entidade. Sabendo quais seriam os nossos beneficiários diretamente, partimos para a construção da atividade de educação ambiental que seria desenvolvida em toda a bacia: Oficina do Livro "Águas e Paisagens Educativas da Bacia Tietê-Jacaré”. Essa oficina, com duração de 4 horas, foi dividida em dois momentos: Teórico e Prático. Para o aperfeiçoamento de tal oficina, durante essa primeira etapa do projeto, foram realizadas duas atividades para testar a metodologia: a primeira junto a alunos da ACIEPE - Atividade Curricular de Integração entre Ensino, Pesquisa e Extensão da Universidade Federal de São Carlos e a segunda junto aos integrantes do Coletivo Educador Tietê-Jacaré. A partir dessas oficinas testes, a metodologia foi ajustada para uma melhor compreensão da atividade e melhor definição de cada etapa. Além disso, a equipe do Instituto Pró-Terra seguiu com reuniões internas, a fim de elaborar o cronograma de ações. Foi elaborada uma carta de orientações para as secretarias e um convite padrão para as instituições, os quais seguiriam juntos ao folder de divulgação do projeto para todos os municípios. Vale ressaltar que a carta de orientações foi um importante instrumento para que os representantes dos municípios, nossos apoiadores, ainda que monitorados a todo instante pela equipe do projeto, fizessem corretamente a divulgação e a formação do grupo que participaria da oficina, entendendo a importância de seu envolvimento e a necessidade de termos a maior heterogeneidade de instituições possíveis dentro do grupo participante da atividade proposta. Como já mencionado acima, as atividades de educação ambiental que foram desenvolvidas nesse projeto foi em forma oficina, a Oficina do Livro "Águas e Paisagens Educativas da Bacia Tietê-Jacaré", a qual teve duração de 4 horas, estando dividida em dois momentos:

1.4.1 Teórico: Que teve como objetivo incentivar a utilização do livro como ferramenta para o desenvolvimento de ações de educação ambiental na Bacia Tietê-Jacaré, uma vez que o livro foi feito especificamente para essa bacia. Além disso, buscou-se sensibilizar o grupo com relação ao pertencimento de cada um a essa paisagem, a Bacia Tietê-Jacaré, com a 


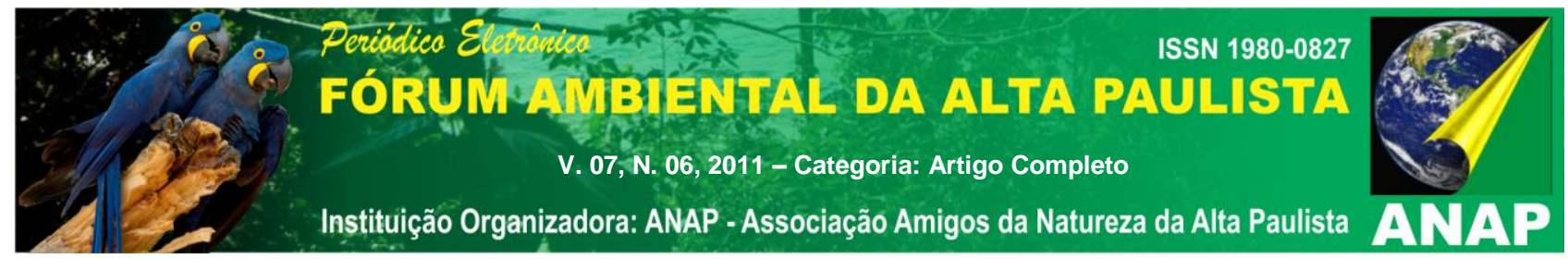

proposta de unirmos esforços para a transformação da realidade de cada município e, assim, da bacia como um todo.

1.4.2 Prático: Nesse segundo momento, foi realizada uma atividade que se utilizou da metodologia pesquisa-ação. Para o desenvolvimento da oficina prática, os participantes foram divididos em grupos de quatro ou cinco pessoas, como apresenta a Figura 1. Esse momento da atividade de educação ambiental, a oficina prática, foi dividido em 6 etapas. Primeiramente, cada grupo construiu um desenho que representou a percepção do mesmo sobre o seu município como uma paisagem educativa, escolhendo os elementos e lugares que julgaram importantes. Na paisagem educativa construída pelo grupo, foram inseridos os 3 principais problemas socioambientais do município onde estávamos. Após essas duas primeiras etapas, foi deixado um tempo de 15 minutos para as(os) educadoras(es) olharem atentamente o livro "Águas e Paisagens Educativas da Bacia TietêJacaré", em especial o conteúdo "Cardápio de Atividades" sugerido para uma paisagem. Feita essa observação, foram escolhidas algumas atividades de educação ambiental que poderiam ser realizadas na paisagem educativa construída pelo grupo. Posteriormente, pensando nas possibilidades que um cardápio de atividades oferece e nas atividades escolhidas pelos grupos, os mesmos montaram um roteiro socioambiental para o seu município, para toda a paisagem educativa construída. E, por último, foram respondidas as fichas de avaliação individual. É importante ressaltar que no convite padrão foi solicitado às instituições que levassem ofícios de requerimento de doação do livro, já que, após o término da oficina, o Instituto Pró-Terra fez o sorteio de alguns exemplares para os participantes levarem às suas instituições. As oficinas foram realizadas em todos os 34 municípios da Bacia Tietê-Jacaré e também em São Pedro, município com parte de seu território nessa bacia.

\section{CONCLUSÃO:}




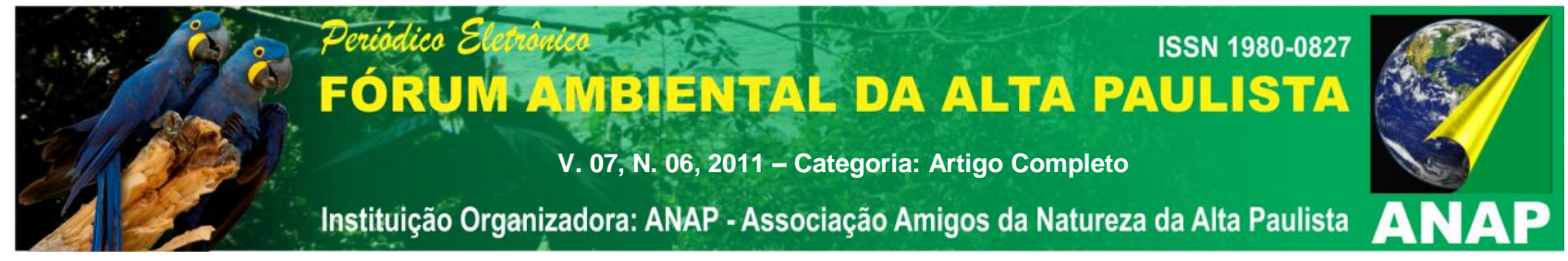

O desenvolvimento do projeto "Educação Ambiental para as Águas da Bacia Tietê-Jacaré" foi, com certeza, de extrema importância para a nossa bacia, sendo possível graças ao financiamento do FEHIDRO. O objetivo principal do projeto foi compreendido pela grande maioria dos municípios, havendo, desta forma, a capacitação direta de 748 educadoras(es) da Bacia Tietê-Jacaré de um total de 473 Instituições distintas, as(os) quais tem, a partir desse projeto, o conhecimento da existência de um Material Didático de Educação Ambiental muito importante, que servirá de guia para o desenvolvimento de novos processos educativos socioambientais. Além disso, as(os) educadoras(es) que puderam participar da atividade de educação ambiental desse projeto compreenderam a importância de se tornarem multiplicadores do conhecimento adquirido e atores de novos trabalhos de educação ambiental, sendo isso percebido através das falas das(os) mesmas(os) no final de cada oficina. Vale ressaltar que o projeto "Educação Ambiental para as Águas da Bacia Tiête-Jacaré" teve repercussão na mídia local de diferentes municípios, já havendo com isso uma grande difusão do processo para além dos participantes. Sem dúvida alguma, o livro foi muito bem aceito por todos os participantes das oficinas, ficando nítido o entusiasmo frente ao produto apresentado. Principalmente nos municípios onde ainda pouco se trabalha com a Educação Ambiental, surgiram ao final da oficina muitos comentários positivos referente à ajuda que o material e a oficina trariam para o desenvolvimento de projetos socioambientais no município. A partir de colocações feitas pelos participantes, ficou claro que o fato de cada grupo já sair da oficina com um Roteiro Socioambiental pronto para ser desenvolvido fez com que as(os) educadoras(es) saíssem do processo mais encorajados, mais acreditados do potencial de cada um. Além disso, com o desenvolvimento desse projeto, acabamos por construir um banco de educadoras(es) ambientais que servirá, certamente, para muitos outros projetos a serem desenvolvidos, facilitando o envolvimento e a formação de parcerias entre os diferentes atores socioambientais da nossa Bacia Tietê-Jacaré. A partir de nossas avaliações continuadas e também a partir da avaliação aplicada a cada indivíduo participante das oficinas, percebemos que ainda existe uma enorme carência de projetos socioambientais voltados para a capacitação de educadoras(es) ambientais de nossa bacia Tiête-Jacaré. Na avaliação aplicada, por exemplo, a grande maioria dos participantes respondeu nunca ter participado de uma atividade como a desenvolvida. 


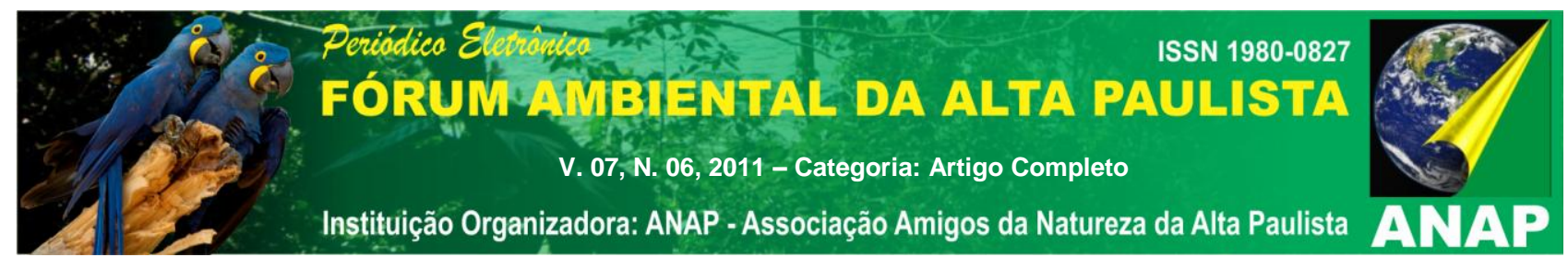

Também nos deparamos com muitos participantes que esperavam que fossem abordadas mais especificamente algumas problemáticas e/ou potencialidades de nossa bacia, demonstrando a necessidade de novas capacitações nesse sentido.

\section{REFERÊNCIAS}

THIOLLENT, Michel. Metodologia da Pesquisa-Ação. São Paulo: Cortez, 1996, p.14

DIONNE, Hugues.A Pesquisa Ação para o Desenvolvimento local. Trad. Michael Thiollent. Brasília: Liber,2007,p.26-27.

Relatório Final ㄲo 40.674.. COMITE DE BACIAS HIDROGRAFICAS TIETÊ-JACARÉ: Diagnóstico da situação atual dos Recursos Hídricos e estabelecimento de diretrizes técnicas para a elaboração do Plano da Bacia Hidrográfica do Tietê/Jacaré 